\title{
Bilateral thoracic paravertebral block combined with general anesthesia vs. general anesthesia for patients undergoing off-pump coronary artery bypass grafting: a feasibility study
}

\author{
Lixin Sun ${ }^{1 \dagger}$, Qiujie $\mathrm{Li}^{1+}$, Qiang Wang ${ }^{1}$, Fuguo Ma ${ }^{1}$, Wei Han ${ }^{2^{*}}$ (i) and Mingshan Wang ${ }^{1}$
}

\begin{abstract}
Background: Whether thoracic paravertebral block (PVB) is useful in patients undergoing off-pump coronary artery bypass grafting $(O P C A B G)$ remains unknown. This study aimed to investigate the feasibility of bilateral PVB combined with general anesthesia (GA) in patients undergoing OPCABG.

Methods: This feasibility study assessed 60 patients scheduled for OPCABG at the Qingdao Municipal Hospital in 2016-2017. Patients were randomly assigned to receive nerve stimulator-guided bilateral PVB combined with GA (PVB $+G A)$ or GA alone ( $n=30 /$ group). Patients were asked to rate rest and cough pain hourly after the surgery. The primary endpoint was the visual analogue scale (VAS) pain score within $48 \mathrm{~h}$ postoperatively. Secondary endpoints were rescue analgesia and morphine consumption, fentanyl dose within $48 \mathrm{~h}$ postoperatively, as well as operative time, time to extubation, intensive care unit (ICU) stay, hospital stay and other postoperative adverse events.

Results: Both rest and cough pains were lower in the PVB + GA group at 12, 24, 36, and $48 \mathrm{~h}$ after surgery compared with the GA group. There were fewer patients who needed rescue analgesia in the PVB + GA group at 12 and $24 \mathrm{~h}$ than in the GA group. Morphine consumptions at 24 and $48 \mathrm{~h}$ were lower in the PVB $+G A$ group compared with the GA group. Time to extubation $(P=0.035)$ and ICU stay $(P=0.028)$ were shorter in the PVB $+G A$ group compared with the GA group. AEs showed no differences between the two groups.
\end{abstract}

Conclusions: Nerve stimulator-guided bilateral thoracic PVB combined with GA in OPCABG is associated with a reduced rescue analgesia and morphine consumption, compared to GA.

Keywords: Nerve block, Thoracic vertebra, Anesthesia, General

\section{Background}

Off-pump coronary artery bypass grafting (OPCABG) is a type of bypass surgery performed on beating heart, without cardiopulmonary bypass (CPB). OPCABG has been developed in Russia mainly to avoid the complications of CPB [1]. The popularity of OPCABG has been declining over the past years in developed countries, but

\footnotetext{
* Correspondence: sallyhan1@163.com

† Lixin Sun and Qiujie Li contributed equally to this work.

2Department of Respiratory Medicine, Qingdao Municipal Hospital, 1

Jiaozhou Road, Qingdao 266011, Shandong, China

Full list of author information is available at the end of the article
}

the rate of OPCABG is currently increasing in some countries such as China and India [2]. Nevertheless, the benefits of OPCABG are debatable [3] and it could benefit only some selected patients [4-6].

Thoracic epidural anesthesia (TEA) has been successfully applied in heart surgery and confirmed to have a myocardial protective effect [7-10]. Nevertheless, a cardiac surgery is usually performed in patients receiving anticoagulant therapy and may be associated with an increased risk of an epidural hematoma. The incidence of epidural hematoma has been estimated to be between 1: 150,000 and 1:1528 [11]. Furthermore, TEA may also be

(c) The Author(s). 2019 Open Access This article is distributed under the terms of the Creative Commons Attribution 4.0 International License (http://creativecommons.org/licenses/by/4.0/), which permits unrestricted use, distribution, and 
complicated by hypotension, urinary retention and pulmonary complications related to respiratory muscle blockade in some patients [12,13]. Although a clinical study [14] has revealed important benefits for TEA in cardiac surgery, its use is still debatable because of the potential risks.

Recently, there has been increasing interest in alternative regional techniques, particularly thoracic paravertebral block (PVB), which offers optimal pain control with a better side effects profile $[15,16]$. Compared with TEA, PVB can provide comparable pain relief, fewer complications, faster recovery, shorter hospitalization, and lower incidence of postoperative chronic pain [17, 18].

The safety and efficacy of segmental PVB has been reported for postoperative analgesia after modified minimally invasive Heart-Port access cardiac surgery [19], but whether bilateral thoracic paravertebral block can be safely and effectively used in OPCABG remains unknown. We hypothesized that PVB could be useful in patients undergoing OPCABG. Therefore, this study aimed to investigate the feasibility of bilateral PVB combined with general anesthesia (GA) in patients undergoing OPCABG, assessing pain (visual analogue scale [VAS] as primary endpoint and rescue analgesia and morphine consumption within $48 \mathrm{~h}$ postoperatively, operative time, dose of fentanyl, time to extubation, intensive care unit (ICU) stay, hospital stay, intraoperative parameters (e.g. bradycardia, tachycardia, hypotension and hypertension) and postoperative adverse events (AEs) as secondary endpoints. This was a pilot study comparing PVB combined with GA vs. GA alone in order to observe the advantages and disadvantages of PVB.

\section{Methods}

\section{Patients and study design}

This was a feasibility study of patients scheduled to undergo OPCABG at the Qingdao Municipal Hospital between July 2016 and May 2017. All patients received preoperative physical examination and plain X-ray. The inclusion criteria were: 1) planned to undergo OPCABG; 2) $50-75$ years old; 3 ) body mass index (BMI) $<30 \mathrm{~kg} /$ $\mathrm{m}^{2}$; 4) ASA II or III; and 5) elective surgery. The exclusion criteria were: 1) spine malformation; 2) vertebral space-occupying lesion; 3 ) infection at the site of paravertebral injection; 4) left ventricular ejection fraction (LVEF) < 40\%; 5) endocrine disease; 6) metabolic disease; 7) extracorporeal circulation; 8) allergies; 9) severe hepatic (alanine transaminase [ALT] or aspartate transaminase $[\mathrm{AST}]>3$ times the upper limit of normal) or renal dysfunction (serum creatinine $[\mathrm{SCr}]>178 \mathrm{mmol} / \mathrm{L}$ and blood urea nitrogen $[\mathrm{BUN}]>9 \mathrm{mmol} / \mathrm{L}$ ); 10) valvular disease; 11) intra-aortic balloon pump; or 12) neurologic or psychotic disorders. The study was approved by the ethics committee of Qingdao Municipal Hospital (No.
20140806-1). Each patient provided a written informed consent.

\section{Randomization and blinding}

The patients were randomized using sequential sealed envelopes prepared by an independent statistician using a computer-generated random number table. Patients were randomly divided into two groups: the bilateral thoracic PVB combined with GA group (PVB + GA group), and the GA group (GA group). The postoperative assessors were blinded to grouping.

\section{Anesthesia}

All patients received their usual medication on the day of operation, followed by premedication with intramuscular morphine $0.1 \mathrm{mg} / \mathrm{kg}$ and midazolam $0.05 \mathrm{mg} / \mathrm{kg}$. Upon arrival in the operating room, 100\% oxygen was administered, and peripheral vein Ringer lactate solution was infused at $6-8 \mathrm{ml} / \mathrm{kg} / \mathrm{h}$.

The patients were monitored with radial artery pressure, heart rate (HR), electrocardiogram (ECG), oxygen saturation $\left(\mathrm{SpO}_{2}\right)$, end-tidal carbon dioxide $\left(\mathrm{ETCO}_{2}\right)$, and other hemodynamic parameters using a Datex multi-parameter monitor (GE Healthcare, Waukesha, WI, USA). The flow-directed pulmonary artery catheter and central venous catheter (Arrow International Inc., Asheboro, NC, USA) were placed through the right internal jugular vein in both groups.

In the PVB +GA group, bilateral thoracic PVB was performed according to the nerve stimulator-guided technique [20-23] combined with the loss of resistance technique for proper location of the paravertebral space (PVS). Briefly, patients in the right lateral decubitus position received intradermal lidocaine $(1 \%)$ at $\mathrm{T}_{3-4}$ PVS. An insulated needle attached to a nerve stimulator was advanced between the transverse process of the third and fourth vertebrae, and the current intensity of the nerve stimulator was set to $2-5 \mathrm{~mA}$ during initial simulation, and subsequently reduced to $0.4-0.8 \mathrm{~mA}$. PVS could also be identified with the "loss-of-resistance" technique to ensure technical success [23, 24], but neuromuscular stimulation was the primary criterion in cases in which loss of resistance could not be felt. After ensuring the absence of blood, air, or cerebrospinal fluid, a 20G catheter was passed through the needle, with 3 $\mathrm{cm}$ of the catheter left in the PVS.

After the catheters had been secured, the patient was turned onto the supine position. $0.375 \%$ of ropivacaine $20 \mathrm{ml}$ were injected by 2 time with $5 \mathrm{~min}$ interval $(5 \mathrm{ml}$ in the first time and $15 \mathrm{ml}$ in the second time), followed by $0.375 \%$ of ropivacaine infused at $5 \mathrm{ml} / \mathrm{h}$ until $30 \mathrm{~min}$ before the end of operation [25]. Analgesia block levels were tested by the pinprick method at the middle of the chest. If analgesia block level was less than 2 
dermatomes, the patient was withdrawn. Bilateral thoracic PVB was not performed in the GA group.

All patients in both groups received GA. GA was induced by midazolam $0.05 \mathrm{mg} / \mathrm{kg}$, etomidate $0.3 \mathrm{mg} / \mathrm{kg}$, fentanyl $4 \mu \mathrm{g} / \mathrm{kg}$, and vecuronium $0.1 \mathrm{mg} / \mathrm{kg}$. After endotracheal intubation, patients were mechanically ventilated to maintain $\mathrm{ETCO}_{2}$ between 35 and $40 \mathrm{mmHg}$. The nasopharyngeal temperature and urine volume were monitored. Warming blankets were used to maintain the nasopharyngeal temperature at $36.5-37.5^{\circ} \mathrm{C}$. Anesthesia was maintained by sevoflurane 1 MAC. Fentanyl 10$20 \mu \mathrm{g} / \mathrm{kg}$ and vecuronium $0.1 \mathrm{mg} / \mathrm{kg}$ were given when indicated. At the end of the operation, the catheter was removed in the PVB + GA group in order to observe the effect of PVB on postoperative morphine use. All patients in both groups were transferred to the intensive care unit (ICU) without extubation. Beginning at the end of the operation, all patients in both groups received patient-controlled analgesia (PCA) using morphine (1 $\mathrm{mg} / \mathrm{ml}$ ) for $48 \mathrm{~h}$ at a loading dose of $2 \mathrm{mg}$, continuous infusion dose of $0.5 \mathrm{mg} / \mathrm{h}$, bolus of $1 \mathrm{mg}$, locking time of $10 \mathrm{~min}$, and maximum dose of $20 \mathrm{mg} / 4 \mathrm{~h}$.

\section{Assessments}

Using the visual analogue scale (VAS; $0 \mathrm{~mm}=$ no pain, $100 \mathrm{~mm}=$ worst pain imaginable), the patients were asked to rate their pain at rest and during coughing every hour after their arrival and return to consciousness in ICU. If the VAS score was $>5$ at rest, rescue analgesia was given with morphine $5 \mathrm{mg}$ IV.

Intraoperative adverse events (AEs), including bradycardia, tachycardia, hypotension, hypertension, and postoperative AEs were recorded. Bradycardia was defined as a heart rate $<50 \mathrm{bpm}$ and treated with intravenous atropine $0.01 \mathrm{mg} / \mathrm{kg}$. Tachycardia was defined as a heart rate $>90 \mathrm{bpm}$ and treated with intravenous esmolol 20 mg. Hypotension was defined as a $20 \%$ decrease in systolic blood pressure (SBP) from baseline and treated with intravenous noradrenaline $5 \mu \mathrm{g}$. Hypertension was defined as a $20 \%$ increase in SBP from baseline and treated with intravenous urapidil hydrochloride $10 \mathrm{mg}$. All hemodynamic drugs were repeated as required.

\section{Endpoints}

The primary endpoint was the pain scores within $48 \mathrm{~h}$ postoperatively. The secondary endpoints were the rescue analgesia and morphine consumption, dose of fentanyl within $48 \mathrm{~h}$ postoperatively, as well as operative time, time to extubation (defined as the time from the end of surgery to the extubation), ICU stay, hospital stay and postoperative AEs (including bradycardia, tachycardia, hypotension and hypertension).

\section{Statistical analysis}

Since this was a pilot study, the sample size was estimated by referring to similar studies [26] rather than an accurate calculation. Continuous data (age, BMI, morphine consumption, operative time, dose of fentanyl, time to extubation, ICU stay, and hospital stay) were expressed as mean \pm standard deviation (SD) and analyzed using Student $t$ test for intergroup comparisons. Categorical data (gender, ASA score, diabetes mellitus, chronic obstructive pulmonary disease, renal dysfunction, hypertension, rescue analgesia, and intraoperative and postoperative AEs) were expressed as frequency (percentage) and analyzed using the chisquare test. Ranked data (rest pain score and cough pain score) were expressed as median [IQR] and analyzed using the Wilcoxon rank sum test. All variables, except for pain scores, were baseline characteristics or secondary endpoints. Statistical analysis was performed using PASW Statistics 18.0 (SPSS Inc., Chicago, NY, USA). Two-sided $P$-values $<0.05$ were considered statistically significant.

\section{Results}

\section{Patients}

Figure 1 presents the patient flowchart. One hundred and fifty-two patients met the inclusion criteria and 92 of them were excluded from the study, including $27 \mathrm{pa}$ tients due to BMI over $30 \mathrm{~kg} / \mathrm{m}^{2}, 18$ patients due to LVEF $<40 \%, 12$ patients due to severe hepatic or renal dysfunction, 10 patients due to carotid artery stenosis or other vascular diseases, 6 patients due to neurologic disorders and 19 patients due to withdrawal of consent. Sixty patients underwent randomization, with 30 patients in each group. One patient was withdrawn from the study due to the failure of PVB on one side and received GA alone. Table 1 presents the baseline characteristics of the patients.

\section{Postoperative pain}

Both rest and cough pain scores were lower in the $\mathrm{PVB}+\mathrm{GA}$ group at $12,24,36$, and $48 \mathrm{~h}$ after surgery compared with the GA group (rest pain: $12 \mathrm{h:} 3[2,3]$ vs. $3[3,3], P=0.004 ; 24$ h: $3[2,3]$ vs. $3[3,4], P=0.007 ; 36$ h: $3[2,3]$ vs. $3[2,4], P=0.018$; 48 h: $2[2,3]$ vs. $3[3,4]$, $P=0.010$; cough pain: 12 h: $4[3,4]$ vs. $4[4,5], P=0.007$; 24 h: $3[3,5]$ vs. $4[4,5], P=0.017 ; 36$ h: $4[3,5]$ vs. $5[3$, 6], $P=0.048 ; 48$ h: $4[3,4]$ vs. $5[3,6], P=0.023)$. There were fewer patients who received rescue analgesia at 12 and $24 \mathrm{~h}$ in the PVB + GA group than in the GA group ( 12 h: $0 \%$ vs. $16.7 \%, P=0.034 ; 24$ h: $3.4 \%$ vs. $20.0 \%, P=$ 0.049). The number of patients who received rescue analgesia at 36 and $48 \mathrm{~h}$ in the two groups were similar. Morphine consumption at 24 and $48 \mathrm{~h}$ was lower in the $\mathrm{PVB}+\mathrm{GA}$ group compared with the GA group $(24 \mathrm{~h}$ : 


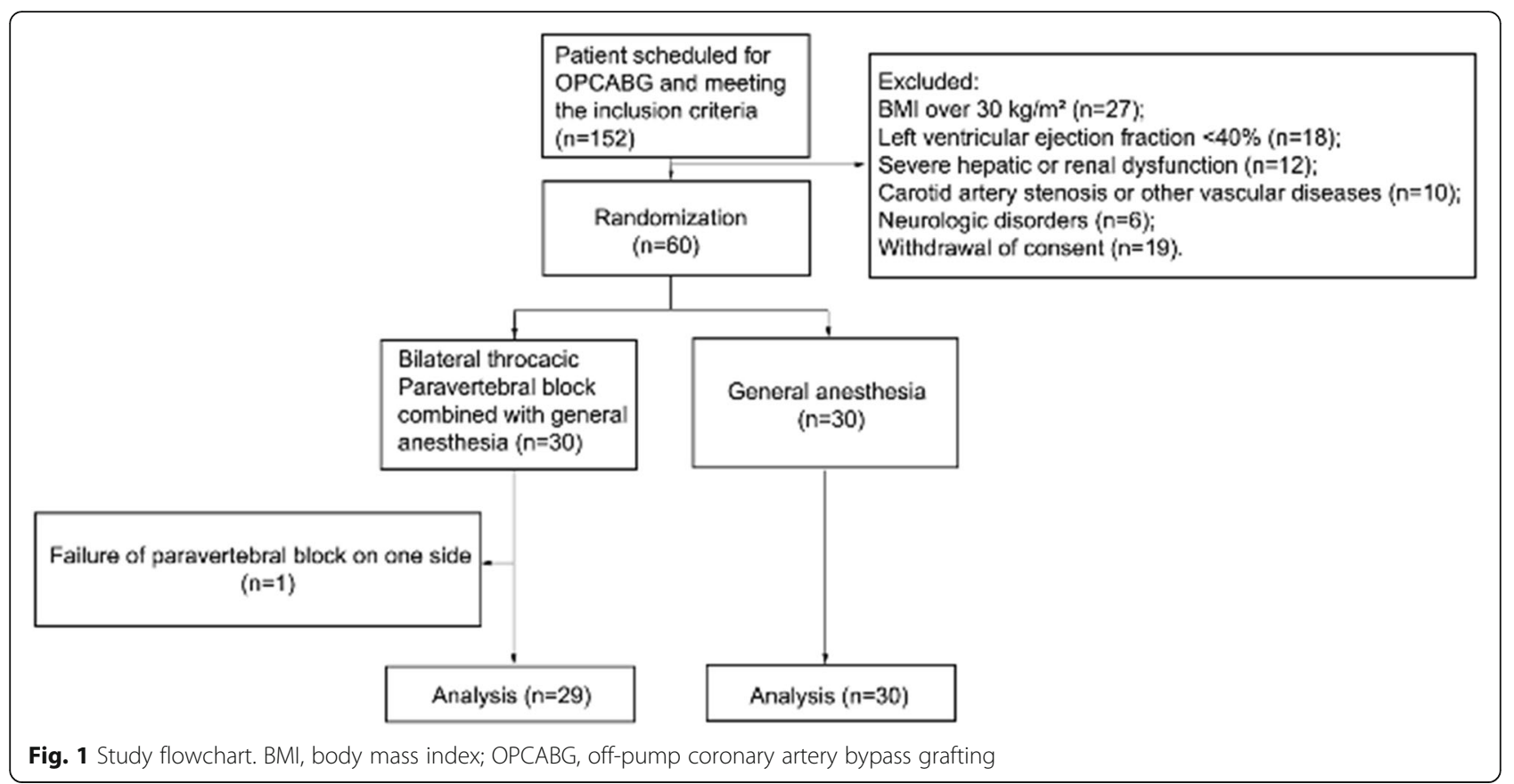

$25.6 \pm 7.3$ vs. $30.7 \pm 9.0 \mathrm{mg}, P=0.033 ; 48 \mathrm{~h}: 47.6 \pm 13.5$ vs. $54.3 \pm 16.1 \mathrm{mg}, P=0.041$ ) (Table 2).

\section{Clinical characteristics}

Table 3 shows that the time to extubation was shorter in the PVB + GA group compared with the GA group (5.8 \pm 1.5 vs. $7.3 \pm 1.7 \mathrm{~h}, P=0.035)$, as well as the ICU stay $(16.3 \pm 3.7$ vs. $20.2 \pm 4.1 \mathrm{~h}, P=0.028)$. The dose of fentanyl was lower in the PVB + GA group compared with the GA group $(1.2 \pm 0.2$ vs. $1.5 \pm 0.3 \mathrm{mg}, P=0.022)$. There were no differences in operative time and hospital stay between the two groups.

Table 1 Baseline characteristics of the patients

\begin{tabular}{|c|c|c|}
\hline Characteristics & $\mathrm{PVB}+\mathrm{GA}(n=29)$ & $\mathrm{GA}(n=30)$ \\
\hline Male, n (\%) & $23(79.3)$ & $21(70.0)$ \\
\hline Age (years) & $68.2 \pm 10.5$ & $70.6 \pm 11.7$ \\
\hline $\mathrm{BMI}\left(\mathrm{kg} / \mathrm{m}^{2}\right)$ & $23.0 \pm 6.6$ & $24.2 \pm 5.1$ \\
\hline ASA (II/III) & $7 / 10$ & $9 / 9$ \\
\hline LVEF (\%) & $55.8 \pm 8.1$ & $56.6 \pm 10.7$ \\
\hline $\mathrm{DM}, \mathrm{n}(\%)$ & $13(44.8)$ & $15(50.0)$ \\
\hline COPD, n (\%) & $3(10.3)$ & $5(16.7)$ \\
\hline Renal dysfunction, n (\%) & $3(10.3)$ & $2(6.7)$ \\
\hline Hypertension, n (\%) & $20(69.0)$ & $18(60.0)$ \\
\hline
\end{tabular}

\section{Adverse events}

Table 4 presents the intraoperative and postoperative AEs in the two groups. The occurrences of tachycardia $(3.4 \%$ vs. $27.8 \%, \mathrm{P}=0.035)$ and hypertension $(0 \%$ vs. $16.7 \%, P=0.008$ ) were lower in the PVB + GA group compared with the GA group. There were no differences in the occurrences of bradycardia, hypotension, and postoperative AEs between the two groups.

\section{Discussion}

It is unknown whether thoracic PVB can be used in patients undergoing OPCABG. Therefore, this pilot study aimed to investigate the feasibility of bilateral PVB combined with GA in patients undergoing OPCABG. The results showed that nerve stimulator-guided bilateral thoracic PVB combined with GA could be efficient in OPCABG to provide high-quality analgesia. However, these findings should be interpreted with caution as non-anticoagulated patients were not assessed in this study. In addition, the risk of AEs is rather difficult to estimate, especially in case of small sample size.

Thoracic spinal nerve block has been clinically used since as early as 1905 and has become more popular in recent years due to a number of advantages: simple application, low failure rate, satisfactory analgesia, and less influence on respiration and circulation [26-28]. Previous studies reported unilateral thoracic nerve block combined with GA applied as analgesia in minimally invasive direct coronary artery bypass (MIDCAB) [29-31]. Satisfyingly, unilateral thoracic nerve block combined with GA exhibited remarkable efficacy in postoperative pain relief, while maintaining stable hemodynamics and 
Table 2 Comparison of VAS scores, rescue analgesia and morphine consumption between groups

\begin{tabular}{|c|c|c|c|c|c|c|}
\hline Variable & Group & $\mathrm{n}$ & PCA $12 \mathrm{~h}$ & PCA $24 \mathrm{~h}$ & PCA $36 \mathrm{~h}$ & PCA $48 \mathrm{~h}$ \\
\hline \multirow[t]{3}{*}{ Rest pain } & $P V B+G A$ & 29 & $3[2,3]$ & $3[2,3]$ & $3[2,3]$ & $2[2,3]$ \\
\hline & GA & 30 & $3[3,3]$ & $3[3,4]$ & $3[2,4]$ & $3[3,4]$ \\
\hline & $P$ & & 0.015 & 0.023 & 0.026 & 0.042 \\
\hline \multirow[t]{3}{*}{ Cough pain } & $P V B+G A$ & 29 & $3[2,3]$ & $3[2,3]$ & $3[2,3]$ & $2[2,3]$ \\
\hline & GA & 30 & $3[3,3]$ & $3[3,4]$ & $3[2,4]$ & $3[3,4]$ \\
\hline & $P$ & & 0.023 & 0.030 & 0.027 & 0.034 \\
\hline \multirow[t]{3}{*}{ Rescue analgesia } & $P V B+G A$ & 29 & $0(0)$ & $1(3.4)$ & $3(10.3)$ & $2(6.9)$ \\
\hline & GA & 30 & $5(16.7)$ & $6(20.0)$ & $6(20.0)$ & $7(23.3)$ \\
\hline & $P$ & & 0.034 & 0.049 & 0.302 & 0.079 \\
\hline \multirow[t]{3}{*}{ Morphine consumption } & $P V B+G A$ & 29 & - & $25.6 \pm 7.3$ & - & $47.6 \pm 13.5$ \\
\hline & GA & 30 & - & $30.7 \pm 9.0$ & - & $54.3 \pm 16.1$ \\
\hline & $P$ & & & 0.033 & & 0.041 \\
\hline
\end{tabular}

VAS Visual analogue scale, PCA Patient-controlled analgesia, PVB Paravertebral block, GA General anesthesia

less postoperative complications [29-31]. In this study, both rest and cough pain scores were lower in patients undergoing OPCABG and fewer patients received rescue analgesia within $24 \mathrm{~h}$ postoperatively in the PVB $+\mathrm{GA}$ group compared with the GA group. However, it should be noted that similar numbers of patients received rescue analgesia at $36 \mathrm{~h}$ and $48 \mathrm{~h}$ in both groups. These findings indicate some improvement in analgesia with PVB + GA compared with GA alone. Therefore, PVB may exert beneficial effects in patients undergoing OPCABG, which deserves further investigation.

Our study is the first comparative study to evaluate bilateral preoperative thoracic paravertebral block applied to patients undergoing OPCABG. We found that the thoracic nerve block segment was about 5 dermatomes in the PVB + GA group, which is in accordance with the imaging results from Christopher et al. [25] Our results also showed that a lower dosage of fentanyl was used during the operation and less PCA morphine was consumed at 24 and $48 \mathrm{~h}$ postoperatively. The extubation time and length of stay in the ICU were shorter in the PVB + GA group, but these factors have little clinical impact, if any.

As is well known, pneumothorax, puncturing of blood vessels, local hematoma, hypotension, and epidural block

Table 3 Clinical characteristics of the patients

\begin{tabular}{llll}
\hline Variable & PVB $+\mathrm{GA}(\mathrm{n}=29)$ & $\mathrm{GA}(\mathrm{n}=30)$ & $P^{*}$ \\
\hline Operative time $(\mathrm{min})$ & $168 \pm 23$ & $176 \pm 28$ & 0.279 \\
Dose of fentanyl $(\mathrm{mg})$ & $1.2 \pm 0.2$ & $1.5 \pm 0.3$ & 0.022 \\
Time to extubation (h) & $5.8 \pm 1.5$ & $7.3 \pm 1.7$ & 0.035 \\
ICU stay (h) & $16.3 \pm 3.7$ & $20.2 \pm 4.1$ & 0.028 \\
Hospital stay (d) & $9.6 \pm 2.1$ & $10.1 \pm 2.3$ & 0.459 \\
\hline PVB Paravertebral block, GA General anesthesia, ICU Intensive care unit. *All \\
variables were analyzed using Student t test
\end{tabular}

are common complications of thoracic PVB [32, 33]. Fortunately, no local anesthetic toxicity event occurred in the present study. The rate of AEs was not different in both groups. It is worth noting that the biggest PVS is close to the $T_{1-2}$ or $T_{2-3}$ intervertebral space, so it is safest to puncture at this site, as the risk for pneumothorax will be lower due to the greater distance between the parietal pleura and pyramis. That is also the reason why we chose $\mathrm{T}_{3-4}$ as the puncture point, which is close to $\mathrm{T}_{1-2}$ or $\mathrm{T}_{2-3}$ PVS, as it increased puncture reliability and reduced $\mathrm{AE}$ occurrence. In addition, anesthesia was terminated at $30 \mathrm{~min}$ before the end of the operation in this study, for the following reasons: 1) to achieve better postoperative analgesia; 2) to assess safety issues due to a high level of monitoring after cardiac surgery; and 3) since $15 \mathrm{ml}$ of drug was injected on each side, PVB was

Table 4 Intraoperative and postoperative AEs

\begin{tabular}{llll}
\hline Variable, $\mathrm{n}(\%)$ & $\mathrm{PVB}+\mathrm{GA}(\mathrm{n}=29)$ & $\mathrm{GA}(\mathrm{n}=30)$ & $P^{*}$ \\
\hline Intraoperative AE & & & \\
Bradycardia & $5(17.2)$ & $3(10.0)$ & 0.334 \\
Tachycardia & $1(3.4)$ & $5(27.8)$ & 0.035 \\
Hypotension & $13(44.8)$ & $10(33.3)$ & 0.262 \\
Hypertension & $0(0)$ & $5(16.7)$ & 0.008 \\
Postoperative AE & & & \\
Nausea & $1(3.4)$ & $3(10.0)$ & 0.612 \\
Vomiting & $0(0)$ & $1(3.3)$ & 1.000 \\
Pulmonary infection & $0(0)$ & $1(3.3)$ & 1.000 \\
Atelectasis & $1(3.4)$ & $1(3.3)$ & 1.000 \\
Reoperation & $0(0)$ & $1(3.3)$ & 1.000 \\
Paresthesia & $1(3.4)$ & $0(0)$ & 0.492 \\
\hline
\end{tabular}

AE Adverse event, PVB Paravertebral block, GA General anesthesia. *All variables were analyzed using chi-square test 
prone to exert minimal impact on hemodynamics, ensuring stable circulation.

Hypotension is an $\mathrm{AE}$ that occurs in about $4 \%$ of pediatric patients [32]. In breast cancer surgery, PVB did not induce hypotension in any of the patients [34, 35]. Similar results were observed in healthy volunteers [36]. Nevertheless, PVB has a lower risk of hypotension than thoracic epidural analgesia $[26,37,38]$. In the present study, no hypotension occurred in the PVB + GA group, suggesting that hypotension is not a major risk in these patients. Nevertheless, this could vary among different populations of patients with different conditions. This warrants additional study.

In the present study, neuromuscular stimulation was used for PVB instead of the ultrasound-guided approach, which is now considered the best approach for PVB [39]. Nevertheless, neuromuscular stimulation is still a valid approach for PVB [22, 23, 40]. China is a developing country that is still adapting to modern approaches. Our hospital has just purchased the ultrasonography (USG) equipment, and the Anesthesiologist have not yet grasped the USG-guided technique. In addition, the learning curve of USG is steep [41]. Hence, even the nerve stimulator has been used in our hospital for many years, the nerve stimulator-guided technique was adopted in the present study until recently.

The present study is not without limitations. Despite the randomization, blinding, and control group, this was a pilot study with a small sample size from a single center. Since this was a pilot study, the sample size was estimated by referring to similar studies [26] rather than accurate calculation. In addition, our reduced sample does not allow any conclusions to be drawn about the safety of the procedure, whether for the morbidity of the technique or for the toxicity of local anesthetics. Our future multicenter randomized controlled trial will have a rigorous sample size calculation based on the results of the present study. Additional studies are necessary to confirm the effect of PVB for OPCABG.

\section{Conclusions}

In conclusion, nerve stimulator-guided bilateral thoracic PVB combined with GA could be used efficiently in OPCABG with reduced rescue analgesia and morphine consumption. Additional studies are necessary to examine the potential AEs.

\section{Abbreviations}

AE: Adverse event; ALT: Alanine transaminase; ANOVA: Analysis of variance; AST: Aspartate transaminase; BMI: Body mass index; BUN: Blood urea nitrogen; Cl: Cardiac index; CPB: Cardiopulmonary bypass; CVP: Central venous pressure; ECG: Electrocardiogram; $\mathrm{ETCO}_{2}$ : End-tidal carbon dioxide; GA: General anesthesia; HR: Heart rate; ICU: Intensive care unit; LVEF: Left ventricular ejection fraction; MAP: Mean arterial pressure; MIDCAB: Minimally invasive direct coronary artery bypass; MPAP: Mean pulmonary arterial pressure; OPCABG: Off-pump coronary artery bypass grafting; PCA: Patient- controlled analgesia; PCWP: Pulmonary capillary wedge pressure; PVB: Paravertebral block; PVRI: Pulmonary vascular resistance index; PVS: Paravertebral space; SBP: Systolic blood pressure; SCr: Serum creatinine; SD: Standard deviation; $\mathrm{SpO}_{2}$ : Oxygen saturation; SVRI: Systemic vascular resistance index; TEA: Thoracic epidural anesthesia; USG: ultrasonography; VAS: Visual analogue scale

\section{Acknowledgements}

Not applicable.

\section{Authors' contributions}

LXS carried out the studies, and drafted the manuscript. QJL, QW and FGM performed the statistical analysis and helped to collect the data. $\mathrm{WH}$ and MSW helped to revise the manuscript. All authors read and approved the final manuscript.

\section{Funding}

This study was supported by the Scientific and Technological Development Guidance Program of Qingdao, China (No. KJZD-13-14-NSH).

\section{Availability of data and materials}

All necessary data supporting our findings has been presented within the manuscript. The datasets used and/or analyzed during the current study are available from the corresponding author on reasonable request.

\section{Ethics approval and consent to participate}

The study was approved by the ethics committee of Qingdao Municipal Hospital (No. 20140806-1). Each patient provided a written informed consent.

\section{Consent for publication}

Not applicable.

\section{Competing interests}

The authors declare that they have no competing interests.

\section{Author details}

'Department of Anesthesiology, Qingdao Municipal Hospital, Qingdao 266011, Shandong, China. ${ }^{2}$ Department of Respiratory Medicine, Qingdao Municipal Hospital, 1 Jiaozhou Road, Qingdao 266011, Shandong, China.

Received: 17 April 2018 Accepted: 24 May 2019

Published online: 12 June 2019

\section{References}

1. Jensen BO, Hughes P, Rasmussen LS, Pedersen PU, Steinbruchel DA. Cognitive outcomes in elderly high-risk patients after off-pump versus conventional coronary artery bypass grafting: a randomized trial. Circulation. 2006;113:2790-5.

2. Taggart DP. Off-pump coronary artery bypass grafting (OPCABG)-a 'personal' European perspective. J Thorac Dis. 2016:8:S829-S31.

3. Moller CH, Penninga L, Wetterslev J, Steinbruchel DA, Gluud C. Off-pump versus on-pump coronary artery bypass grafting for ischaemic heart disease. Cochrane Database Syst Rev. 2012;14:CD007224.

4. Shroyer AL, Grover FL, Hattler B, Collins JF, McDonald GO, Kozora E, et al. On-pump versus off-pump coronary-artery bypass surgery. N Engl J Med. 2009;361:1827-37.

5. Lamy A, Devereaux PJ, Prabhakaran D, Taggart DP, Hu S, Paolasso E, et al. Effects of off-pump and on-pump coronary-artery bypass grafting at 1 year. N Engl J Med. 2013;368:1179-88.

6. Diegeler A, Borgermann J, Kappert U, Breuer M, Boning A, Ursulescu A, et al. Off-pump versus on-pump coronary-artery bypass grafting in elderly patients. N Engl J Med. 2013:368:1189-98.

7. Neskovic V, Milojevic P. High thoracic epidural anesthesia in coronary surgery. Med Pregl. 2003;56:152-6.

8. Palomero Rodriguez MA, Suarez Gonzalo L, Villar Alvarez F, Varela Crespo C, Moreno Gomez Limon I, Criado Jimenez A. Thoracic epidural anesthesia decreases C-reactive protein levels in patients undergoing elective coronary artery bypass graft surgery with cardiopulmonary bypass. Minerva Anestesiol. 2008;74:619-26. 
9. Kessler P, Neidhart G, Bremerich DH, Aybek T, Dogan S, Lischke V, et al. High thoracic epidural anesthesia for coronary artery bypass grafting using two different surgical approaches in conscious patients. Anesth Analg. 2002;95: 791-7 table of contents.

10. Salvi L, Sisillo E, Brambillasca C, Juliano G, Salis S, Marino MR. High thoracic epidural anesthesia for off-pump coronary artery bypass surgery. Cardiothorac Vasc Anesth. 2004;18:256-62.

11. Ho AM, Chung DC, Joynt GM. Neuraxial blockade and hematoma in cardiac surgery: estimating the risk of a rare adverse event that has not (yet) occurred. Chest. 2000:117:551-5.

12. Conlon NP, Shaw AD, Grichnik KP. Postthoracotomy paravertebral analgesia: will it replace epidural analgesia? Anesthesiol Clin. 2008;26:369-80 viii.

13. Olivier JF, Bracco D, Nguyen P, Le N, Noiseux N, Hemmerling T, et al. A novel approach for pain management in cardiac surgery via median sternotomy: bilateral single-shot paravertebral blocks. Heart Surg Forum. 2007;10:E357-62.

14. Hemmerling TM, Le N, Olivier JF, Choiniere JL, Basile F, Prieto I. Immediate extubation after aortic valve surgery using high thoracic epidural analgesia or opioid-based analgesia. J Cardiothorac Vasc Anesth. 2005;19:176-81.

15. Richardson J, Lonnqvist PA. Thoracic paravertebral block. Br J Anaesth. 1998; 81:230-8.

16. Tighe SQ. Paravertebral block. Anaesthesia. 2002:57:511-2 author reply 2 .

17. Joshi GP, Bonnet F, Shah R, Wilkinson RC, Camu F, Fischer B, et al. A systematic review of randomized trials evaluating regional techniques for postthoracotomy analgesia. Anesth Analg. 2008;107:1026-40.

18. Davies RG, Myles PS, Graham JM. A comparison of the analgesic efficacy and side-effects of paravertebral vs epidural blockade for thoracotomy--a systematic review and meta-analysis of randomized trials. Br J Anaesth. 2006:96:418-26.

19. Carmona P, Llagunes J, Casanova I, Mateo E, Canovas S, Martin E, et al. Continuous paravertebral analgesia versus intravenous analgesia in minimally invasive cardiac surgery by mini-thoracotomy. Rev Esp Anestesiol Reanim. 2012:59:476-82.

20. Wheeler $\amalg$. Peripheral nerve stimulation end-point for thoracic paravertebral block. Br J Anaesth. 2001:86:598-9.

21. Boezaart AP, Raw RM. Continuous thoracic paravertebral block for major breast surgery. Reg Anesth Pain Med. 2006;31:470-6.

22. Naja MZ, Ziade MF, Lonnqvist PA. General anaesthesia combined with bilateral paravertebral blockade (T5-6) vs. general anaesthesia for laparoscopic cholecystectomy: a prospective, randomized clinical trial. Eur J Anaesthesiol. 2004:21:489-95.

23. Naja ZM, Raf M, El Rajab M, Ziade FM, Al Tannir MA, Lonnqvist PA. Nerve stimulator-guided paravertebral blockade combined with sevoflurane sedation versus general anesthesia with systemic analgesia for postherniorrhaphy pain relief in children: a prospective randomized trial. Anesthesiology. 2005;103:600-5.

24. Canto M, Sanchez MJ, Casas MA, Bataller ML. Bilateral paravertebral blockade for conventional cardiac surgery. Anaesthesia. 2003;58:365-70.

25. Harle CC, Su G. Paravertebral analgesia for cardiac surgery. Tech Reg Anesth Pain Manag. 2008;12:57-63.

26. Baidya DK, Khanna P, Maitra S. Analgesic efficacy and safety of thoracic paravertebral and epidural analgesia for thoracic surgery: a systematic review and meta-analysis. Interact Cardiovasc Thorac Surg. 2014;18:626-35.

27. Thavaneswaran P, Rudkin GE, Cooter RD, Moyes DG, Perera CL, reports MGJB. Paravertebral block for anesthesia: a systematic review. Anesth Analg. 2010:110:1740-4.

28. Junior Ade P, Erdmann TR, Santos TV, Brunharo GM, Filho CT, Losso MJ, et al. Comparison between continuous thoracic epidural and paravertebral blocks for postoperative analgesia in patients undergoing thoracotomy: systematic review. Braz J Anesthesiol. 2013;63:433-42.

29. Dhole S, Mehta Y, Saxena H, Juneja R, Trehan N. Comparison of continuous thoracic epidural and paravertebral blocks for postoperative analgesia after minimally invasive direct coronary artery bypass surgery. J Cardiothorac Vasc Anesth. 2001;15:288-92

30. Mehta Y, Arora D, Sharma KK, Mishra Y, Wasir H, Trehan N. Comparison of continuous thoracic epidural and paravertebral block for postoperative analgesia after robotic-assisted coronary artery bypass surgery. Ann Card Anaesth. 2008;11:91-6.

31. Mehta $Y$, Swaminathan M, Mishra Y, Trehan N. A comparative evaluation of intrapleural and thoracic epidural analgesia for postoperative pain relief after minimally invasive direct coronary artery bypass surgery. Cardiothorac Vasc Anesth. 1998;12:162-5.
32. Naja Z, Lonnqvist PA. Somatic paravertebral nerve blockade. Incidence of failed block and complications. Anaesthesia. 2001:56:1184-8.

33. Richardson J, Lonnqvist PA, Naja Z. Bilateral thoracic paravertebral block: potential and practice. Br J Anaesth. 2011;106:164-71.

34. Weltz CR, Greengrass RA, Lyerly HK. Ambulatory surgical management of breast carcinoma using paravertebral block. Ann Surg. 1995;222:19-26.

35. Pusch F, Freitag H, Weinstabl C, Obwegeser R, Huber E, Wildling E. Singleinjection paravertebral block compared to general anaesthesia in breast surgery. Acta Anaesthesiol Scand. 1999;43:770-4.

36. Saito T, Den S, Cheema SP, Tanuma K, Carney E, Carlsson C, et al. A singleinjection, multi-segmental paravertebral block-extension of somatosensory and sympathetic block in volunteers. Acta Anaesthesiol Scand. 2001;45:30-3.

37. Koyyalamudi VB, Arulkumar S, Yost BR, Fox CJ, Urman RD, Kaye AD. Supraclavicular and paravertebral blocks: are we underutilizing these regional techniques in perioperative analgesia? Best Pract Res Clin Anaesthesiol. 2014;28:127-38.

38. Bigeleisen PE, Goehner N. Novel approaches in pain management in cardiac surgery. Curr Opin Anaesthesiol. 2015;28:89-94.

39. Okajima $H$, Tanaka O, Ushio M, Higuchi $Y$, Nagai $Y$, lijima $K$, et al. Ultrasoundguided continuous thoracic paravertebral block provides comparable analgesia and fewer episodes of hypotension than continuous epidural block after lung surgery. J Anesth. 2015;29:373-8.

40. Naja MZ, Ziade MF, Lonnqvist PA. Nerve-stimulator guided paravertebral blockade vs. general anaesthesia for breast surgery: a prospective randomized trial. Eur J Anaesthesiol. 2003;20:897-903.

41. Stolz LA, Cappa AR, Minckler MR, Stolz U, Wyatt RG, Binger CW, Amini R, Adhikari S. Prospective evaluation of the learning curve for ultrasoundguided peripheral intravenous catheter placement. J Vasc Access. 2016;17: 366-70.

\section{Publisher's Note}

Springer Nature remains neutral with regard to jurisdictional claims in published maps and institutional affiliations.
Ready to submit your research? Choose BMC and benefit from:

- fast, convenient online submission

- thorough peer review by experienced researchers in your field

- rapid publication on acceptance

- support for research data, including large and complex data types

- gold Open Access which fosters wider collaboration and increased citations

- maximum visibility for your research: over $100 \mathrm{M}$ website views per year

At $\mathrm{BMC}$, research is always in progress.

Learn more biomedcentral.com/submissions 